\title{
A CIDADE E OS MUSEUS: COGNIÇÃO E TECNOLOGIAS EM QUESTÃO
}

\author{
THE CITY AND ITS MUSEUMS: COGNITION \\ AND TECHNOLOGY IN QUESTION
}

\section{LA CIUDAD Y LOS MUSEOS: ESTUDIO DE LA COGNICIÓN Y LA TECNOLOGÍA}

\author{
Cristina Carvalho
}

Pontifícia Universidade Católica do Rio de Janeiro (PUC-Rio), Rio de Janeiro/RJ - Brasil

\begin{abstract}
REsumo O presente artigo aborda aspectos relacionados aos espaços não formais de educação, na perspectiva da cidade educadora, e o potencial dos museus no uso de tecnologias digitais para ampliar experiências educativas. Desse modo, são então analisadas algumas ações que vêm sendo desenvolvidas nessa área e que incorporam a cidade como ambiente de educação e memória coletiva de uma comunidade, a partir dos artefatos nos quais a memória é acionada e interpretada. Constata-se que o uso de ambientes virtuais e de tecnologias digitais tem se apresentado de modo cada vez mais recorrente em museus, modificando experiências corporais e culturais, e expandindo os espaços de aprendizagem. Palavras-chave: Cidade; Museus; Tecnologias; Cognição.
\end{abstract}

Abstract This article examines aspects related to non-formal educational spaces, from the perspective of "the educating city", and the potentials of museums for using digital technologies in order to amplify educational experiences. From this perspective, specific experiences being developed in this field that incorporate the city as a communal environment of education and collective memory will be analyzed, particularly, with respect to the artefacts in which memory is incorporated and interpreted. The use of virtual environments and digital technology is increasingly frequent in museums, transforming bodily and cultural experience, and expanding the spaces of education.

Key-words: City; Museums; Technologies; Cognition. 
Resumen Este artículo analiza aspectos relacionados con los espacios de educación no formal, con la perspectiva de ciudad educadora, y el potencial de los museos en el uso de las tecnologías digitales para ampliar las experiencias educativas. Desde esta perspectiva, se analizan algunas de las experiencias que se han desarrollado en esta área y que incorporan la ciudad como entorno de educación y memoria colectiva de una comunidad, a partir de dispositivos en los que se incorpora la memoria y la interpreta. Se encuentra que el uso de entornos virtuales y tecnologías digitales se presentan cada vez más recurrente en los museos, cambiando experiencias físicas y culturales, y contribuyendo para la ampliación de los espacios de aprendizaje.

Palabras clave: Ciudad; Museos; Tecnologías; Cognición.

\section{INTRODUÇÃo}

Nos dias atuais, é preciso reconhecer uma educação que passa pela importância de perceber-se os novos cenários do processo de ensino e aprendizagem de modo mais amplo do que os modelos tradicionais dos últimos anos, e assinalar a presença de processos educacionais fora dos espaços formais de educação. Para Asencio e Pol (2002, p. 21), esferas sociais distintas - o patrimônio natural, o patrimônio cultural, a própria sociedade e seu funcionamento e o cenário virtual - educam e têm características e objetivos específicos, que absolutamente não são redutíveis entre si. Na perspectiva dos autores, um museu, um monumento, um passeio pela cidade, um fórum de discussão virtual ou mesmo um tema exposto em sala de aula são cenários de aventuras intelectuais e, por isso, compartilham chaves didáticas que vão além de meras coincidências.

A escola, portanto, deixou de ser o único lugar de legitimação do saber, em função da legitimação social de uma variedade de saberes que circulam por outros canais, difusos e descentralizados. "Vivemos num ambiente de informação que recobre e mistura vários saberes e formas muito diversas de aprender, ao mesmo tempo que se encontra fortemente descentrado em relação ao sistema educativo que ainda nos rege, organizado em torno da escola e do livro" (MARTIN-BARBERO, 2006, p. 56).

As reflexões sobre o processo de ensino-aprendizagem e acerca da cognição ultrapassam a sala de aula e as práticas escolares, e trazem à tona aspectos relacionados aos novos cenários educacionais. A cognição resulta da interação entre cérebro, corpo e ambiente, e por isso a promoção de aprendizagens mais qualificadas, no âmbito escolar, implica levar em conta o papel desempenhado também pelos espaços educacionais não escolares. Desse modo, para que a escola possa desempenhar seu papel na formação das novas gerações e cumprir de maneira efetiva a função que lhe cabe como educação formal, vale ampliar o olhar para a própria cidade e para espaços não formais de educação, mais especificamente para os museus.

Este texto aborda então aspectos relacionados aos espaços não formais de educação, na pespectiva da cidade educadora, e o potencial dos museus no uso de tecnologias digitais para ampliar experiências educativas. $\mathrm{O}$ uso de ambientes virtuais e de tecnologias digitais 
tem se apresentado de modo cada vez mais recorrente em museus, modificando experiências corporais e culturais, e expandindo os espaços de aprendizagem. O artigo apresenta e analisa algumas experiências que vêm sendo desenvolvidas nessa área e que incorporam a cidade como ambiente de educação e memória coletiva de uma comunidade, a partir dos artefatos nos quais a memória é incorporada e interpretada.

\section{RETOMANDO O TEMA DA CIDADE EDUCADORA}

"Saber orientar-se numa cidade não significa muito. No entanto, perder-se numa cidade, como alguém se perde numa floresta, requer instrução" (BENJAMIN, 1995, p. 73). Refletindo sobre a experiência nas cidades, o autor nos leva a pensar nos usos que os seres humanos dão aos espaços que compõem as cidades. O termo cidade educadora estabeleceu-se na Grécia clássica e, assim como várias expressões, foi sendo retomado, esquecido, reelaborado. No final do século XX, ganhou força novamente entre alguns estudiosos que apontam para um aspecto em comum: toda cidade - compreendida como espaço de educação não formal - é potencialmente educadora. As distintas maneiras de viver, ver, ouvir e sentir a cidade, e as intervenções de diferentes públicos mostram que os sujeitos reconstroem os espaços que compõem a cidade através de suas experiências, de suas memórias e de invenções, e que esse espaço abre-se como possibilidade educativa, para além das instituições convencionais e tradicionais de educar (TRILLA, 1997).

Portanto, esse não é um tema novo. Autores clássicos da sociologia e da antropologia mencionam a importância da cidade como espaço de aprendizagem e de socialização. No texto "A metrópole e a vida mental", Georg Simmel (1987, p. 13) afirma que os problemas mais graves da vida moderna derivam da reivindicação do indivíduo de preservar sua autonomia e individualidade em face das esmagadoras forças sociais, da herança histórica, da cultura externa e da técnica de vida. O autor faz uma comparação interessante entre cultura objetiva, que seria a cultura ligada a objetos, conhecimento, coisas, instituições, e a cultura subjetiva, que estaria ligada ao indivíduo. Para Simmel (1987), há uma diferença no ritmo de crescimento das duas culturas: enquanto a cultura objetiva ascendeu aceleradamente, motivada pela divisão do trabalho e sua crescente especialização, a cultura subjetiva cresceu lentamente ou pode até mesmo ter regredido em aspectos como ética e idealismo. "Não é preciso mais do que apontar que a metrópole é o genuíno cenário dessa cultura que extravasa de toda vida pessoal" (SIMMEL, 1987, p. 23). O autor capta uma ambiguidade da individualização na modernidade: a maior liberdade individual caminha lado a lado com a maior impessoalidade, objetivação e instrumentalização das relações sociais. Ou seja, com a modernidade, o contato humano e as relações sociais foram acelerados e ficaram mais objetivos e impessoais; logo, mais superficiais.

A cidade tornou-se um objeto de preocupação entre estudiosos da América Latina, mais significativamente na década de 1960, integrando as reflexões sobre urbanização e desenvolvimento em "países periféricos” (GARCIA-CANCLINI, 2001; QUIJANO, 2000). Para Garcia-Canclini (2001, p. 118), a concepção europeia de cidade como núcleo de vida 
cívica, cultural, acadêmica e comercial perdeu importância, e as megalópoles latino-americanas têm se transformado em cenários caóticos de mercados informais, exploração e redes de solidariedade ou de violência. "Na Europa fala-se de um 'renascimento das cidades' e as cidades latino-americanas são cada vez mais sedes de catástrofes".

De acordo com a Organização das Nações Unidas (ONU), desde 2007 mais de 50\% da população mundial vive nas grandes cidades. Na América Latina, a taxa alcança o nível de $75 \%$. Estudos promovidos pela ONU apontam que, em 2030, dois terços da população mundial viverão em centros urbanos, acarretando o surgimento de megalópoles de mais de 20 milhões de moradores. ${ }^{1}$ As projeções indicam que as cidades do planeta deverão somar seis bilhões de habitantes em 2045, o que apresentará a países em desenvolvimento diversos desafios para saciar as necessidades de habitação, infraestrutura, transporte, energia, emprego, saúde e, principalmente, educação. Nesse contexto, o papel das cidades educadoras adquire ainda mais relevância.

Refletindo sobre a temática da cidade, Lopes (2000, p. 68) apresenta dois polos para descrever imagens da cidade: aspectos positivos da urbanização - mobilidade, proximidades das fontes de informação e das novas tecnologias, escolarização, nível de vida -, e traços sombrios de uma patologia urbana, como a insegurança, a violência e a solidão. Entre os aspectos positivos, vale lembrar as discussões em torno da potencialidade da cidade e reconhecer a existência de outros contextos e dinâmicas sociais geradoras de aprendizagens que podem (e devem) interagir com as práticas institucionais. Na verdade, a qualidade das relações e dos processos de cognição e mediação são questões que acompanham a própria história da humanidade. Como cultivar relações humanas eficazes em cidades que se reconfiguram a cada momento? Que espaços existem para que as pessoas se relacionem, aprendam, produzam conhecimento?

Por sua vez, nos grandes centros urbanos, apresenta-se crescente e também preocupante o fechamento de espaços públicos tradicionais destinados à população - principalmente aqueles espaços destinados às crianças e aos jovens. Assim, a maioria das crianças moradoras das metrópoles desconhece o que significa apropriar-se das ruas, nelas brincar, apreciar, desfrutar. Garcia-Canclini (2001), utilizando-se principalmente de dados da Cidade do México, destaca o quanto é baixo o uso das instalações públicas pela população, aspecto constatado em várias cidades da América Latina.

Castro (1998, p. 141) ressalta o quanto a cidade apresenta-se como fundamental para a análise da especificidade das condições de subjetivação contemporânea, problematizando o outro, constituído pela espacialidade urbana: "No destino das cidades residem as possibilidades de construção de uma nova ordem social". É fato que as cidades utilizam novas possibilidades de relações sociais, produzidas, segundo a autora, sobretudo pelos estilos de vida determinados pelo consumo. Mas, na pluralidade das culturas e dos sujeitos humanos,

\footnotetext{
1 As projeções mostram que a urbanização, combinada com o crescimento populacional, pode acrescentar 2,5 bilhões de pessoas às populações urbanas até a metade do século, com quase $90 \%$ desse aumento concentrado na Ásia e na África. Ainda, segundo o estudo, a população urbana mundial cresceu rapidamente de 746 milhões em 1950 para 3,9 bilhões em 2014. A Ásia, sozinha, abriga 53\% desse quinhão, seguida pela Europa (14\%) e pela América Latina (13\%). Fonte principal: www.unhabitat.org.
} 
configuram-se outras maneiras de viver a cidade, e outras estéticas podem ser experimentadas no espaço urbano.

A estética e também a ética das relações nas cidades parecem ter mudado muito com os processos de intensa urbanização. Praças e ruas transformaram-se em lugares de passagem, e as multidões apresentam-se solitárias - são espaços que se desvitalizaram, deslizando progressivamente da categoria de público para a neutralidade do não privado (LOPES, 2000, p. 75). Entretanto, conforme destaca o autor, não se pode considerar que a lógica de apropriação do espaço urbano seja um mero espelho da lógica da produção; ao contrário, muitos conflitos urbanos resultam precisamente da incompatibilidade que entre si essas lógicas manifestam. Mas, com medo da violência, do caos instaurado em muitos centros, a população tem buscado alternativas, reorganizando os espaços, construindo ambientes que vêm ganhando cada vez mais pretensa legitimidade, gerando sensação de segurança e praticidade.

Por último, instituições de naturezas distintas têm representado de modo mais intenso o papel de amplas experiências vividas pelo sujeito no cotidiano, como a televisão, a internet e todos os outros meios de comunicação e de informação. É possível observar nos cotidianos das grandes metrópoles o vaivém cotidiano e as atividades dos sujeitos, a todo o tempo, atravessadas pelos diversos recursos tecnológicos disponíveis, ainda que desigualmente, entre as pessoas. Para Silverstone (2005, p. 18), "há uma tensão constante entre o tecnológico, o industrial e o social, tensão que deve ser levada em conta se queremos reconhecer a mídia como, de fato, um processo de mediação".

\section{A APRENDiZAGEM de CRIANÇAS E JOVENS EM ESPAÇOS URBANOS}

Frente às transformações urbanas, onde os adultos parecem perdidos em suas cidades, como ficam as crianças e os jovens? Que espaços existem para esse público nos grandes centros urbanos? Como se dá sua inserção nos espaços das cidades? Será que, no planejamento urbano, alguém se preocupa com os ambientes destinados a esse segmento? Será que se pensa em espaços que poderiam atender de modo adequado às crianças e aos jovens? Como aliar a familiaridade de crianças e jovens com tecnologias digitais ao conhecimento e à fruição da cidade onde moram? Como explorar as possibilidades de aprendizagem que as novas mídias, aliadas aos espaços da cidade, proporcionam às crianças e aos jovens? A reflexão sobre a necessidade de transposição, para a aprendizagem escolar, das aprendizagens que se configuram no uso que os jovens fazem dos recursos tecnológicos, permite pensar também na transposição das aprendizagens provenientes da experiência em diferentes espaços físicos.

O paradoxo de não saber o que fazer com a população infantil e juvenil nas nossas cidades apresenta-se cada vez mais frequente nos dias atuais. Não tem sido possível proporcionar experiências educativas para esses segmentos no espaço físico e nas instituições que compõem a cidade? Constata-se também dificuldades em lidar com as experiências, cada vez mais intensas e velozes, desses segmentos no mundo virtual e de mediar essas experiências em direção à inserção na cidade e em suas instituições culturais. A responsa- 
bilidade recai, portanto, ainda mais sobre espaços que podem proporcionar experiências diferenciadas e/ou mais ricas para os indivíduos, como no caso dos museus.

As mudanças e transformações pelas quais passa a sociedade são constituintes de nossa identidade e de nosso patrimônio porque, conforme destaca Varine (2012, p. 13), "tudo o que tem sentido para nós, o que herdamos, criamos, transformamos e transmitimos é o patrimônio tecido de nossa vida, um componente da nossa personalidade". Mas o autor complementa que, na maior parte das vezes, não estamos conscientes desse patrimônio, porque a educação que recebemos elimina a sua maior parte, em nome de critérios acadêmicos e estéticos.

A urbanidade apresenta-se como importante característica da cultura contemporânea, pois ela delimita um espaço de compartilhamento de cultura e de práticas simbólicas, um espaço de sociabilidade, de construção da identidade. Conforme destacam Azevedo et al. (2009, p. 5), “uma cidade, enquanto ser coletivo dotado de 'vontade' e 'memória', fabrica para si um repertório de representações e conceitos. A cidade se mostra como um imenso campo de atividades humanas e as construções nada mais são do que a vida se fazendo acontecer". Comungando as reflexões dos autores, a intenção é dialogar com a atividade humana, com os usos e apropriações dos espaços urbanos, com os processos de construção do conhecimento, pois "os espaços vão sendo criados e adaptados a necessidades reais e estão longe de serem simplesmente monumentos desprovidos de vida, que se erguem como representação de um período, apesar de o ser também” (AZEVEDO et al., p. 6).

Em geral, constatamos políticas governamentais ocupando-se do que se acredita ser a preservação da memória e da cultura das cidades, mas, conforme destaca Meneses (2009, p. 32), "a memória é uma construção social que produz documentos de um tempo, e a história a interpretação dessa memória, pela leitura crítica desses mesmos documentos". Entretanto, a história também é a vivência das pessoas e as transformações que elas produzem. E não podemos esquecer o papel da memória coletiva na formação da identidade dos sujeitos. Certamente, aos usos que os sujeitos fazem das tecnologias disponíveis e criadas a cada tempo na história, em um movimento de acoplamento, também se associam diferentes identidades.

Pensando em alguns espaços que compõem as cidades, a opção é trazer especificamente as instituições ligadas à educação não formal, em especial aquelas voltadas à difusão da arte e da ciência. Para Barbosa (2009, p. 21), no Brasil, todas as organizações não governamentais (ONGs) que têm obtido sucesso na educação de segmentos historicamente excluídos ou desprivilegiados estão trabalhando com arte e "até vêm ensinando às escolas formais a lição da arte como caminho para recuperar o que há de humano no ser humano".

A centralidade da arte e da estética no processo de desenvolvimento humano é também encontrada na obra de Vigotski (1999). Para o autor, a arte guarda estreita relação com a vida; seus efeitos só podem ser processados no próprio corpo humano, e seu desenvolvimento não possui explicações místicas, divinas ou religiosas. Nas palavras de Vigotski (1999, p. 308), “a arte está para a vida como o vinho para a uva (...), a arte recolhe da vida o seu material mas produz acima desse material algo que ainda não está nas propriedades 
desse material". Considera que, para que ocorra apropriação da arte por parte dos sujeitos, faz-se necessário a mediação das relações sociais junto ao fruidor, de modo que nele sejam projetados os movimentos que a arte suscita. Para Vigotski (1999, p. 315), "a arte é o social em nós e, se o seu efeito se processa em um indivíduo isolado, isto não significa, de maneira nenhuma, que suas raízes e essências são individuais. O social existe até onde há apenas um homem e as suas emoções".

Silverman (1995) avalia que, nas últimas décadas, a sociedade do conhecimento e da informação tem assistido a uma mudança de paradigma advinda dos desafios que se colocam para essa nova era e participado dela, o que implica a transformação das concepções de informação, comunicação e conhecimento. Por um longo período da história da humanidade, inúmeras informações e vários conteúdos ficaram restritos ao espaço físico de bibliotecas e museus, e agora estão disponíveis em distintos suportes. Ainda que não se apresente de modo universal, as informações podem ser acessadas a qualquer momento por uma parcela significativa da sociedade, mas avançamos pouco nas discussões relativas à emergência de novos modelos cognitivos.

O fato é que os nossos hábitos de vida, integrados às novas tecnologias, foram alterados e provocaram outra forma de comunicação e de contato com a cultura e com o conhecimento. Analisando os novos hábitos culturais, Garcia-Canclini (2007, p. 49-50) ressalta que "as fusões multimídia e as concentrações empresariais na produção de cultura correspondem, no consumo cultural, à integração de rádio, televisão, música, notícias, livros, revistas e internet".

\section{OS MUSEUS E A CONSTRUÇÃO DO CONHECIMENTO}

As novas formas de comunicação e as possibilidades de ensino-aprendizagem que emergem da relação que os usuários estabelecem com elas levaram as instituições culturais, em especial os museus, a perceber a necessidade de se atualizar e de repensar o seu papel, a sua relevância e as suas ações como espaços de mediação na construção do conhecimento. As diferentes definições acerca do papel dos museus na sociedade acentuam a sua dimensão educativa e assumem que ele é, acima de tudo, um espaço de educação não formal. A Associação Americana dos Museus, por exemplo, "atribui o título de museu apenas à instituição que "é essencialmente educativa"” (POULOT, 2013, p. 19), declarando que cerca de $88 \%$ dos museus norte-americanos fornecem programas educativos, centrados em arte, história, matemática ou ciência. Na mesma perspectiva, estudos como o de Carvalho (2013) têm ressaltado que os museus são espaços de aprendizagem e que o trabalho educativo realizado por essas instituições deve promover as experiências dos visitantes com os bens e fenômenos culturais que apresentam, desenvolvendo a sensibilidade sobre o conhecimento e a relação afetiva a respeito da instrução.

A criação de sites, as TICs e a informatização de inventários, por exemplo, são instrumentos que ampliam o universo dos públicos potenciais e permitem projetar a imagem do museu e de suas atividades para além dos meios de comunicação tradicionais. Essa incursão 
por novos domínios da comunicação coloca novos desafios sobre os quais os museus devem interrogar-se. Conforme destaca Castells (2009), os museus precisam decidir se querem tornar-se mausoléus da cultura histórica destinados ao prazer de uma elite global ou podem responder ao desafio de se tornarem conectores culturais para uma sociedade que não sabe mais comunicar-se. Ou seja, “os museus podem continuar 'peças de museu' ou podem se reinventar como protocolos de comunicação para uma nova humanidade" (OLEIRO, 2006, p. 434). Nos dias atuais, já é possível encontrar instituições museológicas que, começando pela utilização da internet para divulgar suas atividades, têm se destacado com páginas na web disponibilizando conteúdos e formatos inovadores de interatividade. Essas instituições submergiram esse mundo virtual com o objetivo de ganhar maior visibilidade social e, por sua vez, perceberam que sua própria função social poderia expandir-se através desse meio.

Nesse contexto, agentes de instituições diversas vêm buscando alternativas para se criar formatos que possam realmente aproveitar a função informativa e educativa do meio virtual. As possibilidades de interação propiciadas pelos meios eletrônicos, nos quais, muitas vezes, o indivíduo é convidado a opinar e a intervir parecem levá-lo a assumir uma postura mais proativa perante a informação, criticando-a, refazendo-a e interagindo com o produtor e com outros usuários. Essa exploração abre o acesso ao mundo, ampliando, portanto, as capacidades perceptivas daqueles que utilizam esses suportes. Para Jenkins (2009, p. 28), o próximo estágio dessa nova era é o da passagem de uma cultura de interação para a cultura participativa, evidenciando uma mudança cultural em curso: um indivíduo que não se contenta mais em consumir um produto, mas quer modificá-lo, criar a partir dele, reinventá-lo, fazer parte.

Assinalando um caminho para pensar na relação entre tecnologias, museus e aprendizagem, Ururahy (2013) buscou compreender o movimento dos museus no mundo das TICs. Em uma primeira fase, os museus caminharam pela internet para uso e distribuição de informações a um público mais amplo; em seguida, investindo na arte computacional, preocuparam-se em oferecer aos visitantes conteúdos diferentes dos que havia nos museus físicos; e chegaram à fase atual, em que as instituições se dispõem a compartilhar a criação e a organização de seus acervos com os usuários e a comunidade. Para a autora, o novo público dos museus, especialmente em seu formato virtual (mas que também está presente em seu espaço físico), "é esse espectador multifunção que não se satisfaz apenas com a relação direcional de receptor da obra. Ele deseja - ou apenas exerce naturalmente - a função de receptor-emissor, criador-difusor" (URURAHY, 2013, p. 344).

Algumas publicações, como o NMC Horizon Report, ${ }^{2}$ têm se dedicado a entender os impactos das novas tecnologias no ambiente museológico e o possível uso em ações educacionais nos próximos anos. As tendências apresentadas nessas publicações são importantes para apoiar gestores de museus em decisões gerenciais, bem como problematizam os principais desafios e restrições que os museus enfrentam ao adotar novas tecnologias. As tecnolo-

2 O NMC Horizon Report faz parte do Projeto Horizon NMC, criado em 2002. É uma publicação internacionalmente reconhecida e representa o esforço de investigação que identifica e descreve as tecnologias emergentes que podem ter grande impacto ao longo dos cinco anos seguintes. 
gias apresentadas em cada edição do NMC Horizon Report estão integradas a um contexto contemporâneo que reflete a situação atual na esfera da educação de museus. O conselho consultivo da publicação realizou uma análise extensiva dos recentes artigos, entrevistas, trabalhos e novas pesquisas para identificar as tendências que afetam a prática educacional e educativa dos museus nos dias de hoje, e exibiu uma lista dos principais vetores de adoção tecnológica em museus para o período entre 2011 e 2016. No topo da lista está a identificação de que "cada vez mais, visitantes e funcionários esperam uma experiência diferenciada em cada dispositivo". ${ }^{3}$ Os visitantes virtuais desejam realizar rápida e facilmente algumas tarefas on-line simples, independentemente do dispositivo que estão utilizando, embora isso seja válido também para os visitantes no espaço físico do museu, onde é comum ver pessoas interagindo com os seus smartphones para decidir que parte da galeria visitarão em seguida. Por esses dispositivos, o mundo mostra-se mais presente para os seus usuários.

Esses novos modos de uso de dispositivos eletrônicos também estão disponíveis para as crianças nos museus? Nesse contexto de busca por outras possibilidades de uso das tecnologias pelos espaços museais, que se configurem como momentos de mediação que transformam a qualidade da atividade humana, Lopes $(2014$, p. 118) destaca uma das iniciativas de um museu na utilização de um recurso midiático:

Na "Sala de Texturas Naïf", as crianças podem tocar nas obras, reconhecendo,
identificando diferentes tipos de materiais como metal, madeira, lã, CDs, pano,
tela, tecidos quentes e frios, camurça etc. A visita é seguida de uma brincadeira
de estátua dos bichos com músicas sobre os mesmos. Na obra Rio de Janeiro,
gosto de você, gosto dessa gente feliz, são realizados jogos de lince. As crian-
ças, na verdade, recebem, em miniatura, um pedaço da obra, em papel, e têm
que identificá-la na tela gigante. São convidadas a relatar lugares que conhe-
cem ou querem saber da paisagem carioca retratada no quadro. Também são
convidadas a identificar na obra os sons que saem do tablet da arteducadora,
de diversos elementos que compõem a paisagem sonora dos bairros cariocas.
Há ainda dois aparelhos tablets, instalados em uma bancada ao lado do quadro
25, com um jogo de elementos presentes na paisagem da obra que as crianças
podem montar recriando à sua maneira.

Esse é um bom exemplo de como a percepção pode ser pensada muito mais em analogia com o tocar do que com o ver. As práticas tradicionalmente realizadas nas galerias de arte pressupõem que podemos ter contato com a obra somente pela visão. Mas, seja pela visão, seja pelo toque, percebemos pela exploração o que está disponível para acessar. Nesse exemplo, as crianças estão explorando com todos os sentidos, acessando, portanto, a obra e construindo outros significados sobre ela. Também, na medida em que a obra é um modelo ou proxy, ${ }^{4}$ cada vez mais do mundo está presente para elas.

3 NMC Horizon Reports. Principais vetores das adoções tecnológicas em museus (2011/2016). In: MENDES, Luis Marcelo (Org.). Reprograme: comunicação, branding e cultura numa nova era de museus. Rio de Janeiro: Imã Editorial, 2012.

4 Proxy é o termo utilizado para definir os intermediários entre o usuário e seu servidor e, portanto, desempenha a função de conexão do computador (local) à rede externa (internet). 
Ainda que exista apenas um tablet para, por exemplo, grupos escolares com mais de 20 crianças, vale ressaltar a iniciativa da instituição em buscar outros suportes para o diálogo com as obras do museu. Conforme destaca Tota (2000, p. 148), a experiência cognitiva e emotiva que as novas formas dialógicas podem favorecer corresponde muito mais ao "perfil do visitante contemporâneo, habituado a fruir diversos media, interativos, habituado a navegar entre os numerosos museus on-line". Por sua vez, o convite feito às crianças para identificar na obra os sons de diversos elementos que compõem a paisagem sonora dos bairros cariocas configura-se como uma iniciativa interessante da equipe do museu. Vale questionar: durante os processos de aprendizagem - formal ou não formal - a que fomos e/ou somos apresentados, que situações podemos destacar de valorização da experiência sonora? Cabe nos perguntarmos se os processos de aprendizagem configurados nos ambientes não formais de educação estão promovendo a exploração dos diferentes sentidos ou se apenas reafirmam a equivocada suposição de que a visão é a fonte principal do conhecimento.

\section{REPROGRAMANDO OS MUSEUS}

Ao longo da História, os museus e centros de ciência estabeleceram uma relação mais próxima com as escolas em decorrência da especificidade dessas instituições, e a interação representou, por muito tempo, quase uma exclusividade dessa tipologia de museu. O uso das novas tecnologias nos museus de ciências também se apresenta de modo mais contundente nesses espaços, no Brasil e em vários países, e é possível localizar ações desenvolvidas nesses museus que buscam uma aproximação com o público em geral, principalmente o escolar. Por exemplo, no projeto (MURRIELO et al., 2005) de construção do Museu de Ciências da Universidade Estadual de Campinas (UNICAMP), inaugurado em 2006, constata-se o desejo da implementação de uma política que compreenda esse espaço como lugar cultural interativo, onde a apresentação das ciências e das tecnologias privilegie múltiplos aspectos relativos aos processos, produtos, ética, estética e relevância social. Ressalta-se ainda, como ponto focal, a integração das ciências com as tecnologias, com as artes e com problemáticas cotidianas contemporâneas.

O Museu de Ciência e Tecnologia de Amsterdã (NEMO) - maior centro científico da Holanda -, está localizado em um prédio de cinco andares em forma de navio e prova que aprender sobre ciência e tecnologia pode ser divertido e descontraído. Todos os sentidos são estimulados por inúmeras atividades interativas, protótipos, exibições, apresentações de teatro, filmes, oficinas e demonstrações. É possível cheirar, ouvir, sentir e ver como o mundo funciona. Mas, para ter essa experiência fascinante, é preciso seguir uma regra do espaço: é proibido não tocar e explorar tudo o que se vê! Mais uma vez, é a exploração pelos sentidos - pelo corpo - que se enfatiza nessa experiência. O público-alvo principal são crianças de 6 a 16 anos de idade, mas o NEMO também ensina algo a respeito de ciência e tecnologia aos seus visitantes adultos.

Atualmente, a interação e o uso das TICs são considerados ferramentas fundamentais de comunicação para qualquer tipologia de museu. Para Sartin (2010, p. 262), a tecnologia 
destaca os conteúdos apresentados pelo museu de modo inovador e facilita a comunicação com o público em geral, especialmente os segmentos jovens, desde que utilizada com responsabilidade e pertinência, fugindo dos eventuais recursos fáceis de pirotecnia expositiva. O que não significa, contudo, que a interatividade promovida por aparatos não computadorizados não seja, como apontado por estudiosos da área, efetiva.

O visitante, principalmente nos dias atuais, ao circular pela exposição de um museu, não busca mais uma experiência meramente contemplativa, até porque perceber não é nada contemplativo. Conforme mencionado por Hughes (2010, p. 154), o visitante espera encontrar alguma forma de participação ou interação com a exposição, como um controle a ser utilizado, um botão a apertar etc. Para Oliveira (2012, p. 185), "mais que lamentar as trocas nas mídias, os museólogos, técnicos e profissionais de museus devem examinar de que maneira isso pode afetar a comunicação que o museu proporciona". Estudos apontam o quanto a inserção das tecnologias no espaço expositivo já não se configura apenas como um aspecto conveniente, mas inevitável. As mudanças tecnológicas e as ferramentas à disposição para a construção de inúmeras possibilidades nos mais diferentes campos permitem, a cada momento, fazer uso de novas mídias. Mesmo para as mais tradicionais exposições, há muitos anos já se discute a adequação de determinadas mídias ou suportes a determinados propósitos. Agora a mesma questão deve ser aplicada às novas tecnologias: que mídias servem a que mensagem?

A eficácia de dispositivos utilizados em muitos museus dentro e fora do Brasil, como totens e audioguias, por exemplo, tem sido questionada em função do isolamento dos visitantes que fazem uso desses equipamentos. As indagações decorrem do entendimento de que as interações sociais no espaço expositivo são de grande valia para a riqueza da experiência do visitante, incluindo o processo de aprendizagem que ela pode acarretar, por dois motivos principais. Em primeiro lugar, a interação social pode ajudar muito na exploração do acervo do museu, levando o visitante a acessar cada vez mais o mundo representado pela exposição e, em segundo lugar, coloca o visitante em contato com a sua tradição cultural ou com a tradição de outros povos, contribuindo, portanto, para a formação de sua identidade pelas narrativas encontradas e pelo esforço de reelaborar sua narrativa pessoal em diálogo com as tradições.

Na perspectiva de Vom Lehn et al. (2010, p. 5), o uso individual de alguns aparatos tecnológicos interativos dificulta a exploração coletiva do equipamento e, ao se planejar uma exposição, é preciso levar em conta que as pessoas, em geral, analisam e compreendem uma exposição pela interação social, não só dentro do grupo que as acompanha, mas também em função de outros visitantes que porventura estejam no mesmo espaço. Hornecker (2008, p. 126) destaca a experiência de alguns museus, como o Berlin Museumfür Naturkunde, que têm tentado aprimorar essa dificuldade com o uso de mesas interativas. Em decorrência da maior dimensão, essas superfícies permitem, em geral, a exploração conjunta do dispositivo por diversos visitantes, evitando as filas que se formam em quiosques individuais. Para o autor, esses aparatos também permitem que alguns visitantes possam apenas observar a interação executada por outros, usufruindo igualmente dos resultados obtidos ou dos textos gerados. 
Também buscando compreender o uso das TICs nos museus, Chelini (2012) apresenta a avaliação da exposição permanente realizada pelo United States Holocaust Memorial Museum, na tentativa de analisar como a tecnologia poderia ser utilizada na exposição visando estender a experiência do visitante para além dos muros. A pesquisa realizada no museu aponta que $31 \%$ dos visitantes gostariam de receber mais informações durante sua visita, enquanto $61 \%$ manifestaram-se a favor da possibilidade de ter acesso a mais informação, mas em outro momento. O responsável pela pesquisa defende que os museus deveriam fazer uso das tecnologias, não para fornecer cada vez mais informações dentro do seu espaço físico, mas para gerar novos vínculos com o público visitante, em momento posterior à visita, e apresenta como estratégia o uso pelo visitante de um cartão que permitiria a coleta por radiofrequência, ao longo da visita, de informações sobre a mostra e/ou pontos específicos dela. Posteriormente, pela internet, o visitante poderia ter acesso a uma página pessoal, onde as informações coletadas no museu apareceriam de maneira organizada, por exemplo, em função das linhas temáticas da instituição. A partir desse ponto, diversas estratégias poderiam ainda ser desenvolvidas, como a criação de grupos on-line de visitantes com interesse em comum. O estudo destaca que o museu poderia, inclusive, a partir dessa tecnologia, mapear os pontos da exposição que despertam maior interesse. Nesse caso, a tecnologia não estaria a serviço do museu apenas no momento da visita, mas permitiria reforçar os laços do museu com o visitante fora de seus muros.

O Museu Van Gogh, em Amsterdã, disponibiliza aplicativos para aparelhos móveis que permitem explorar algumas obras do pintor de modo impressionante: é possível ver grãos de areia na tinta de um dos quadros, olhar sob a moldura de um quadro a fim de iluminar o efeito da descoloração de um pigmento vermelho na pintura de outra obra, aprender acerca do seu método de trabalho ou simplesmente conhecer um pouco mais a respeito da vida e da obra do pintor por meio de cartas - aplicativo que contém esboços, desenhos, pinturas, cartas e vídeo com entrevistas de especialistas do museu sobre as cartas de Van Gogh. Em 2014, essas experiências foram premiadas em categorias de aplicativos para dispositivos móveis por diferentes agências.

Os museus virtuais, do ponto de vista da recepção, são uma novidade cada vez mais difundida e representam ao mesmo tempo uma revolução. Para Tota (2000, p. 175), nesse campo abre-se, portanto, "uma série de questões estruturais para a análise dos processos artísticos, questões essas que assinalam a passagem para formas de arte e de consumo não contíguas relativamente ao passado". Igualmente representam questões a serem analisadas no campo da cognição e da mediação, embora já se configure em objeto de atenção por parte de algumas instituições, que compreendem que mais do que possibilitar uma visita virtual - aspecto comumente oferecido pelos sites eletrônicos -, o objetivo deve ser expandir a experiência museal, "abrir novas janelas de exploração dos temas por meio de roteiros hipermidiáticos, estimular a colaboração dos visitantes com postagem de conteúdos relativos à temática do museu e, no sentido específico das redes sociais, permitir interação entre os visitantes" (COSTA, 2012, p. 204).

O primeiro passo a ser dado nessa direção é o reconhecimento pelos gestores de museus desse cenário e de suas tendências. Essa é uma condição fundamental para garantir a 
relevância, a partir desse momento, pelas suas consequências nos ambientes expositivos e também na interação com os públicos e no entendimento das suas necessidades. Para Mendes (2012, p. 19), vivemos uma época contraditória e excitante para os mais de 55 mil museus de todo o mundo. Se, por um lado, lidamos com dados preocupantes de cortes de orçamento na área da cultura, por outro lado, governos como os da China, Qatar e Emirados Árabes investem milhões de dólares na construção de megamuseus. Essa bipolaridade de euforia e preocupação também apresenta-se quando observamos que todo o elenco de novas tecnologias surge tanto como canal de aproximação das pessoas com os museus como igualmente coloca em questão a própria existência dessas instituições. Ele interroga: "Quais os critérios que serão adotados para a manutenção da sua missão num mundo onde o volume de informações, produtos, manifestações artísticas geradas desafia as ideias tradicionais de preservação, conservação e difusão?” (MENDES, 2012, p. 19).

$\mathrm{Na}$ realidade, o autor faz um convite aos pensadores de museus a reprogramar pensamentos e práticas de gestão na área museológica, destacando o quanto a gestão da comunicação apresenta-se como aspecto fundamental para o recondicionamento dessa instituição ao seu lugar de centralidade no desenvolvimento cultural de um país. As TICs têm forte presença na vida e nas marcas de identidade do universo jovem e estão cada vez mais imbricadas em sua sociabilidade e em sua forma de aprender. Integrá-las nas experiências de aprendizagem promovidas pelos museus pode ser um fator importante para potencializar essas experiências.

$\mathrm{Na}$ perspectiva das instituições, Gaspar (2012) aponta o empreendedorismo criativo digital como elemento-chave para os museus e defende um olhar estratégico das instituições em relação às oportunidades trazidas pela internet e pelas mídias móveis de rentabilizar conteúdos e encontrar parcerias na inovação das tecnologias de informação para a sustentabilidade. Anderson (2006) destaca o tratamento de nicho que as TICs possibilitaram nos mercados atuais, gerando novos negócios e oportunidades de acesso. Para o autor, esse ambiente propicia o surgimento de comunidades que estabelecem ligações no espaço virtual pelos meios de comunicação a distância - comunidades de aprendizagem -, e a dispersão geográfica dos membros passa a ser fator favorável que potencializa o uso dessas tecnologias e minimiza as dificuldades relacionadas a tempo e espaço, promovendo o compartilhamento de informações e a criação de conhecimento coletivo.

Ururahy (2013) destaca iniciativas empreendidas nessa direção por algumas instituições, como o Museu de Arte Moderna de Nova York (MOMA-NY), que se apresenta como um dos museus que têm se utilizado da economia criativa no desenvolvimento de novas relações com o público através de sua página na internet. A instituição não exibe em seu site apenas informações básicas como, por exemplo, sobre a programação, o espaço, as ações educativas, mas traz uma série de propostas de interação do usuário/visitante com o conteúdo e o acervo: visualização 3-D das exposições programadas em Flash; links para páginas de exposições e para um blog do museu; trailers de suas mostras de filmes e vídeos promocionais das exposições; jogos interativos a respeito da arte para o público infanto-juvenil. No site do MOMA estão também disponibilizados, para download gratui- 
to, aplicativos para smartphones que possibilitam que o usuário tenha acesso a informações exclusivas do museu.

O Google Art Project ${ }^{5}$ representa um dos maiores exemplos da tentativa de invadir o mundo das pessoas, ao mesmo tempo cada vez mais individual e mais coletivo. A tecnologia disponível nesse site possibilita que o internauta, por meio de imagens de altíssima resolução, visualize o interior de alguns dos mais importantes museus do mundo. $\mathrm{O}$ ambiente possibilita acesso a vídeos sobre diferentes temas, fornece informações extras a respeito das peças expostas, relaciona outras obras de vários autores, além da possibilidade de zoom em cada obra, e permite que o usuário selecione e salve imagens escolhidas, montando, assim, sua própria coleção - uma das opções do site é a Galeria dos Usuários, que, em 2014, possuía quase 35 mil participantes. Segundo os seus idealizadores, a intenção é que, em curto prazo, essa transmissão de imagens, do espaço do museu para o usuário no computador remoto, seja feita ao vivo.

Há também a iniciativa do Museum with no Frontiers ${ }^{6}$ como mais um exemplo de esforços que têm buscado unir as tecnologias e a comunicação virtual às práticas museológicas, culturais, educativas e artísticas. A ideia é utilizar as tecnologias computacionais para criar museus com coleções que não existem fisicamente, como réplicas de artefatos e até cidades inteiras de civilizações dizimadas. Cabe ressaltar que esse museu tem procurado construir coleções modeladas em 3-D. Assim, o indivíduo pode ter acesso ao mundo passado e presente (e, por que não?, o futuro).

Ainda que de forma tímida, responsáveis pela gestão de alguns museus do Brasil têm desenvolvido experiências positivas e apontado que o uso de TICs potencializa projetos diversificados. O Museu das Minas e do Metal (MMM), aberto ao público em 2010, faz parte do Circuito Cultural Praça da Liberdade, em Belo Horizonte (MG), e abriga um importante acervo sobre mineração e metalurgia. O museu utiliza a tecnologia, de forma lúdica e criativa, como principal linguagem expográfica para apresentar esse universo, tendo sempre o patrimônio histórico, artístico e cultural como contextos. Segundo os gestores do MMM, o site da instituição foi elaborado ao mesmo tempo em que se planejavam e se executavam as obras de adaptação arquitetônica, de restauração e de implementação da museografia.

Em 2008, a Universidade Federal de Santa Catarina (UFSC) publicou o projeto desenvolvido para três fortificações da Ilha de Santa Catarina, sob sua responsabilidade, destacando "as potencialidades da utilização da informação em formato digital e das vantagens dos recursos multimídia como instrumentos de suporte às ações de preservação do patrimônio cultural" (TONERA, 2008, p. 41). Os idealizadores do projeto destacam que os trabalhos realizados pela equipe ao longo dos anos seguintes, sempre dentro da mesma linha de atuação, apenas vieram reforçar a convicção inicial de que a preservação do patrimônio cultural, em qualquer um dos seus múltiplos campos de abordagem e atuação, não pode prescindir dos recursos que os meios computacionais oferecem. "Recursos que já vêm sendo há algum tempo largamente utilizados por outras áreas do conhecimento, mas que no

Disponível em www.google.com/culturalinstitute/project/art-project. Acesso em: maio 2016.

6 Disponível em http://www.discoverislamicart.org/ Acesso em: mar. 2016.

98 Comunicações | Piracicaba | v. 24 | |n. 23| p. 85-103 |setembro-dezembro 2017 
campo do patrimônio cultural ainda são iniciativas raras e isoladas, mesmo fora de nosso país" (TONERA, 2008, p. 50).

\section{Cidade, museus, mediação e tecnologias}

Trilla (1997) destaca que a capacidade de adaptação da cidade em relação às mudanças, visto que o processo educacional não é (e não pode ficar!) estagnado, torna-a mais educadora. Nessa perspectiva, destaca que uma cidade sempre igual a si mesma é uma cidade educativamente obsoleta, em contraposição àquela que é capaz de importar e de exportar experiências educativas, que promove o intercâmbio com outras cidades.

Portanto, a cidade como espaço de aprendizagem, bem como, as questões aqui discutidas a respeito do uso da tecnologia e ambientes virtuais em museus não são contraditórios ou se apresentam como projetos opostos, ao contrário, em diálogo, esse encontro pode configurar-se como aspecto a ser explorado tanto por gestores das cidades como de museus, de modo a potencializar a apropriação desses espaços por crianças e jovens cada vez mais afetos a um mundo conectado.

Em geral, o encontro entre tecnologias interativas e instituições museológicas abriu caminho para inúmeras e diversificadas experiências. É incontestável que o museu virtual permitiu reunir obras não apenas afastadas no espaço, mas também no tempo. O mundo se torna presente para cada vez mais pessoas, não importa onde estejam. Ainda nessa direção, os museus virtuais resolvem categoricamente a questão da incompatibilidade entre fruição e conservação das obras, opção que se torna decisiva nos casos em que a fruição de uma obra represente um dano para a conservação.

Entretanto, conforme destaca Tota (2000, p. 211), uma vez on-line, os museus precisam começar a repensar a si próprios, pois essa nova configuração apresenta-se como uma aplicação que, de algum modo, corrói, nos seus pressupostos de base, a própria definição de museu. Nesse sentido, "o encontro com as tecnologias interativas representa um desafio que, em parte, ainda não foi contado. Com efeito, tratar-se-ia de projetar museus completamente novos, pensados desde o início a partir das potencialidades que as novas tecnologias colocam à disposição".

Trata-se de imaginar novas poéticas do planejamento museológico pensadas para um museu virtual em sentido próprio, ou seja, ações pensadas para um museu que se configure como destituído de qualquer geografia territorial. "Não reprodução-imitação, mais ou menos cuidadosa, de conjuntos de espaços geridos no mundo off-line, mas coleção virtual de objetos, artefatos que, como tal, existem exclusivamente on-line" (TOTA, 2000, p. 211).

Asensio e Pol (2002) destacam a importância de ações consistentes e de uma intervenção planejada. Para os autores, há a necessidade de compor equipes nas quais os profissionais se ocupem, especificamente, das questões relativas à educação.

Os cenários de aprendizagem informal são muito diversos e possuem cada um uma lógica diferente, porém com um grande potencial. Assim, o conservador de museus ou o designer de páginas web, o produtor de programas televisivos, 
o etnógrafo especialista em festas locais ou o biólogo que investiga o entorno ambiental concreto possuem uma bagagem específica nas suas disciplinas de referência, porém raramente controlam, mesmo que minimamente, a problemática da transposição didática e da aprendizagem informal nos contextos mencionados. Em muitas situações, os projetos de aprendizagem informal estão compostos exclusivamente por estes profissionais, às vezes junto aos especialistas encontram-se editores finais dos materiais (designers ou editores) que tampouco controlam o processo subjacente de aprendizagem (ASENSIO e POL, 2002, p. 19).

Conhecer, portanto, o que crianças e jovens são capazes de realizar no campo virtual não é apenas uma exigência da pesquisa nessa área; apresenta-se como uma necessidade de todos os que lidam com educação, formal ou não formal. Para atuarmos como mediadores na relação de crianças e jovens com o mundo por meio das tecnologias digitais, é necessário conhecermos o uso que esses sujeitos fazem da tecnologia.

Os museus (assim como outros equipamentos culturais e a escola) enfrentam o desafio de incluir grande parcela da população que ainda não tem acesso às novas tecnologias e às possibilidades de interação com a cultura e a arte advindas desses suportes. Por isso, a questão da mediação necessária para que crianças e jovens desenvolvam as habilidades e conhecimentos necessários para utilizar as TICs é da maior relevância.

\section{REFERENCIAS}

ANDERSON, Cris. A Cauda Longa: do mercado de massa para o mercado de nicho. Trad. Afonso Celso da Cunha Serra. Rio de Janeiro: Elsevier, 2006.

ASENSIO, Mikel \& POL, Elena. Nuevos escenarios en educación. Aprendizaje informal sobre el patrimonio, los museos y la ciudad. Argentina/Buenos Aires: Aique, 2002.

AZEVEDO, Flávia, CATÃO, Leandro \& PIRES, João (orgs.). Cidadania, memória e patrimônio: as dimensões do museu no cenário atual. Belo Horizonte: Crisálida, 2009.

BARBOSA, Ana Mae. Mediação cultural é social. In: BARBOSA, Ana Mae; COUTINHO, Rejane (orgs.). Arte/educação como mediação cultural e social. São Paulo: Editora UNESP, 2009.

BENJAMIN, Walter. Rua de mão única. Obras escolhidas, v. 2. São Paulo: Brasiliense, 1995.

CARVALHO, Cristina. Criança menorzinha... ninguém merece! - políticas de infância em espaços culturais. In: KRAMER, Sonia \& ROCHA, Eloísa Candal (orgs.). Educação infantil: enfoques em diálogo. São Paulo: Papirus, 2013, p. 295-312.

CASTELLS, Manuel. Museums in the information era: cultural conector of time and space. In: PARRY, Ross (Org.). Museums in a age digital. USA: Routledge, 2009, p. 417434.

CASTRO, Lucia Rabello de (Org.). Infância e adolescência na cultura de consumo. Rio 
de Janeiro: Nau Editora, 1998.

CHELINI, Maria Julia. Novas tecnologias para... novas (?) expografias. In: Museologia e Interdisciplinaridade. Vol. 1, nº. 2, jul./dez. de 2012, p. 59 a 71.

COSTA, Adriana. Rede MMM: cooperação entre o museu e o público. In: MENDES, Luis Marcelo (Org.). Reprograme: comunicação, branding e cultura numa nova era de museus. Rio de Janeiro: Imã Editorial, 2012.

GARCIA-CANCLINI, Néstor. Lectores, espectadores e internautas. Barcelona, España: Editoral Gedisa, 2007.

. Consumidores e cidadãos: conflitos multiculturais da globalização. Rio de Janeiro: Editora UFRJ, 2001.

GASPAR, Ana Paula. Iniciativas digitais em museus. In: MENDES, Luis Marcelo (Org.). Reprograme: comunicação, branding e cultura numa nova era de museus. Rio de Janeiro: Imã Editorial, 2012.

HORNECKER, Eva. "I don't understand it either, but it is cool": visitor interactions with a multi-touch table in a museum. In: IEEE INTERNATIONAL WORKSHOP ON HORIZONTAL INTERACTIVE HUMAN COMPUTER SYSTEMS, TABLETOP, 3, 2008. Proceedings... Amsterdam: IEEE, 2008. p. 121-128. Disponível em: <http://www.ehornecker.de/Papers/BerlinMuseumTabletop08.pdf>. Acesso em: 17 mar. 2015.

HUGHES, Philip. Exhibition design. London: Laurence King Publishing, 2010.

JENKINS, Henry. Cultura da convergência. São Paulo: Aleph, 2009.

LOPES, João Teixeira. A cidade e a cultura: um estudo sobre as práticas culturais urbanas. Portugal: Edições Afrontamento: Câmara Municipal do Porto, 2000.

LOPES, Thamiris. O público infantil no Museu Internacional de Arte Naif do Brasil. Dissertação (Mestrado em Museologia e Patrimônio). UNIRIO, Rio de Janeiro, 2014.

MARTIN-BARBERO, Jesus. Tecnicidades, identidades, alteridades: mudanças e opacidades da comunicação no novo século. In: MORAES, Dênis de. (Org.). Sociedade midiatizada. Rio de Janeiro: Manuad, 2006.

MENDES, Luis Marcelo. De ilhas a plataformas. In: MENDES, Luis Marcelo (Org.). Reprograme: comunicação, branding e cultura numa nova era de museus. Rio de Janeiro: Imã Editorial, 2012.

MENESES, José. Memória e historicidade dos lugares: uma reflexão sobre a interpretação do patrimônio cultural das cidades. In: AZEVEDO, Flávia et al. (orgs.). Cidadania, memória e patrimônio: as dimensões do museu no cenário atual. Belo Horizonte: Crisálida, 2009, p. 32-45.

MURRIELO, Sandra et al. O nascimento do Museu de Ciências da UNICAMP, um novo espaço para a cultura científica, 2005. Disponível em: https://www.mc.unicamp.br/files/ rf48d $924850 \mathrm{~d} 977 / \mathrm{O} \% 20$ nascimento $\% 20 \mathrm{do} \% 20 \mathrm{Museu} \% 20 \mathrm{de} \% 20 \mathrm{Ci} \% \mathrm{C} 3 \% \mathrm{AAncias} \% 20$ da\%20UNICAMP.pdf. Acesso em: 8 abril. 2015. 
OLEIRO, Manuel. Apresentação. In: SEMEDO, Alice \& LOPES, João (coord.). Museus, Discursos e Representações. Porto/Portugal: Edições Afrontamento, 2006.

OLIVEIRA, José. O Museu e a sua arquitetura no mundo globalizado: entre informação e virtualidade. Museologia \& Interdisciplinaridade. Brasília, v. 1, n. 1, jan./jul. 2012.

POULOT, Dominique. Museu e museologia. Belo Horizonte: Autêntica, 2013, p. 15-33.

QUIJANO, Aníbal. Colonialidad del poder, eurocentrismo y América Latina. In: LANDER, Edgardo (Org.). Colonialidad del saber, eurocentrismo y ciencias sociales. Buenos Aires: UNESCO/CLACSO, 2000.

SARTIN, Antonio. A experiência e a experimentação no Museu da Língua Portuguesa: relatos e observações. In: BENCHETRIT, Sarah et al. (org.). Museus e comunicação: exposições como objeto de estudo, 1. ed. Rio de Janeiro: Museu Histórico Nacional, 2010, V. 1, p. 259-272.

SILVERMAN, Lois. Visitor meaning-making in museums for a new age. Curator, v. 38, n. 3, 1995, p. 161-9.

SILVERSTONE, Roger. Por que estudar a mídia? São Paulo: Edições Loyola, 2005.

SIMMEL, Georg. A metrópole e a vida mental. In: VELHO, Otávio G. (Org.). O fenômeno urbano. Rio de Janeiro: Guanabara, 4. ed., 1987, p. 11-25.

TONERA, Roberto. Os recursos computacionais e a preservação do patrimônio cultural: o caso do CD-ROM Fortalezas Multimídia. In: CORREIA, Rosa (Org.). Oficina de Estudos da Preservação. Rio de Janeiro: IPHAN-Rio, 2008.

TOTA, Anna Lisa. A sociologia da arte: do museu tradicional à arte multimídia. Trad. Isabel Teresa Santos. Lisboa: Editorial Estampa, 2000.

TRILLA, Jaime. Ciudades educadoras: bases conceptuales. In: ZAINKO, Maria Amélia S. (Org.). Cidades educadoras. Curitiba: ed. UFPR, p. 13-34, 1997.

URURAHY, Heloisa Pinto. A difusão da arte na era dos museus virtuais. In: ARANHA, Carmen \& CANTON, Cátia (orgs.). Espaços de Mediação: a arte e seus públicos. São Paulo: Museu de Arte Contemporânea da Universidade de São Paulo, 2013, p. 339-350.

VARINE, Hugues. As raízes do Futuro. O patrimônio a serviço do desenvolvimento local. Trad. Maria de Lourdes Parreira Horta. Porto Alegre: Medianiz, 2012.

VIGOTSKI, Lev. Psicologia da Arte. São Paulo: Martins Fontes, 1999.

VOM LEHN, Dirk et al. Rethinking interactivity: design for participation in museums and galleries. Cambridge: Design Office Group, 2010 (Work, interaction \& technology research group). Disponível em: <http://www.eng.cam.ac.uk/DesignOffice/cmt/resources/ pdf/vom_lehnetAl.pdf $>$. Acesso em: 17 mar. 2015. 


\section{Dados da Autora}

\section{Cristina Carvalho}

Doutora em Educação pela PUC-Rio. Professora do Programa de Pós-Graduação do Departamento de Educação da PUC-Rio. Coordenadora do Grupo de Pesquisa em Educação, Museu, Cultura e Infância (GEPEMCI) e do Curso de Especialização em Educação Infantil (PUC-Rio). Rio de Janeiro/RJ - Brasil. cristinacarvalho@puc-rio.br

Submetido em: 30-6-2016

Aceito em: 22-5-2017 